\title{
The costs of high technology
}

$A$ report last week on $X$-ray scanners has raised questions about expensive technology in the US health care system. Colin Norman reports from Washington

IN mid-1973, a sophisticated and very expensive piece of medical equipment was introduced into the United States from Britain. Since then it has found its way into hundreds of hospitals and doctors' offices, and the swiftness with which the new technology has been adopted has generated a major controversy. This has helped shed light on the reasons why hospital costs have risen eight times faster than the cost of living during the past 25 years, and why many people despair that the American health care system can ever be brought under sensible cost controls.

The equipment, known as a computed tomographic (CT) scanner, is a nifty machine which its promoters claim will revolutionise the diagnosis of many medical disorders. Developed by EMI Ltd, the CT scanner is essentially a combination of an X-ray machine and a computer, which provides cross-sectional images of internal body organs. Early models were limited to use on the head, but later and more sophisticated versions can provide images of the internal organs of any part of the body. The scanner's advantage over conventional X-ray machines lies in its ability to produce high quality images of soft tissue structures from numerous angles.

Few people would quarrel with the argument that CT scanners represent a major advance in medical X-ray technology, or that they may be useful diagnostic tools in many instances. The controversy centres on the fact that the technology has been so widely and swiftly adopted in the United States that massive investments have been made before the clinical usefulness of the machines has been well documented.

Although less than four years have elapsed since the first CT scanners were introduced into the United States, an estimated 760 machines have now been installed or are on order. Since each machine has a price tag of between $\$ 300,000$ and $\$ 700,000$ and costs about $\$ 300,000$ a year to operate, hundreds of millions of dollars are being sunk into the technology by American hospitals. A particularly striking indication of the overwhelming demand for the machines is the fact that some 40 orders were placed for EMI's new whole body scanner before the machine was even commercially available. By contrast, in Britain, where CT scanners were originally devloped, only a handful of machines are in operation and fewer than 40 have been ordered.

This overwhelming and seemingly unreserved adoption of CT scanners in the United States led the Health Research Group, an organisation linked with the consumer advocate Ralph Nader, to charge last year that "the purchase of these machines is a particularly striking example of the introduction of extremely expensive medical technology into the health care system before there is adequate evidence that patient benefits or dollar savings exceed costs". The group demanded that a national moratorium be placed on the purchase of CT scanners until the benefits had been better evaluated. And last week, the Institute of Medicine, part of the National Academy of Sciences, said in a carefully worded report that "the long-term effects of CT scanning on medical care and its costs are not yet discernible".

The Institute's report, perhaps the most influential study yet published on the use of CT scanners, is noteworthy as much for what it says about the general problems of controlling hospital costs as for its recommendations about this particular technology.

The report is quick to acknowledge that CT scanners may have many important uses, and it lists some of the areas in which the machines may offer advantages over conventional diagnostic tools. Nevertheless, the Institute notes that conventional techniques may be just as effective and much cheaper in many cases, and "considers it essential ... that controls be placed on the location and use of and charges for CT services". It also recommends that medical insurance companies should not pay for some types of CT scan until there is better evidence of their efficacy.

The question arises as to why the American hospital system has rushed to embrace CT scanners so wholeheartedly. The answer lies in the organisation and funding of the health care system, and the swift adoption of CT scanners epitomises many of the problems inherent in that system.

To begin with, there is little political incentive to hold down the costs of medical care in the United States. The middle classes, where political power largely resides, are generally well protected by private health insurance, and the medical costs incurred by the poor and the aged are met by the federal government. As the Institute puts it in its report, "The growing share of personal health care expenditures covered by third-party reimbursement has reduced the incentives to control use (of expensive technologies), because the physicians decision to use services is separated from the patient's immediate expenses". According to officials in the Department of Health, Education and Welfare, more than $90 \%$ of the $\$ 55,700$ million hospital costs incurred last year were met by private insurance payments or federal Medicare and Medicaid schemes.

The report cites other reasons for the soaring costs, such as "competition among hospitals for medical staff, prestige, or revenues", and it notes that there has been a recent general increase in the use of diagnostic tests stemming partly from fear of malpractice suits, which "encourages defensive medical practice". All of these factors, the Institute states, suggest that "the present organisation of medical care and methods of financing and regulating that care in the United States have encouraged investment in beds and equipment beyond a socially efficient level".

Some states are trying to get a grip on soaring hospital costs through socalled certificate of need laws which require institutions to obtain approval from planning authorities before purchasing expensive equipment. But these laws, for a variety of reasons, have failed to curb the proliferation of CT scanners. The Institute report notes, for example, that some $15 \%$ of the CT scanners installed so far are located in the offices of private physicians, which are exempt from the certificate of need requirements, and "some physicians appear to have deliberately circumvented the intent" of the laws. In one well-publicised case, for example, after a hospital was denied a CT scanner, physicians at the hospital formed a partnership, bought a machine and installed it in an office across the street.

A final incentive for hospitals to purchase CT scanners seems to be their potential for generating revenues. The Institutes report states, for example, that the average charge for a scan is about $\$ 240$, and an independent economic survey of CT scanners published last year indicated that the average machine is used for about 3,000 scans per year. In other words, about $\$ 700,000$ is generated by each machine per year, more than enough to offset the purchase price and operating costs over a very short period.

Given that profit potential, there is some incentive for hospitals to use the machine in cases where less costly, conventional diagnostic equipment would 
- Total spending on research and development in the United States is expected to reach nearly $\$ 41,000$ million this year, according to figures compiled by the National Science Foundation. If the estimates are correct, support for research and development would stay ahead of inflation for the second year running, though the combined two-year increase would not be sufficient to wipe out inflationary losses incurred during the early 1970s.

According to the NSF study, the federal government is expected to spend about $\$ 21,800$ million in 1977 , a $10 \%$ increase over 1976 , while industry is expected to spend about $\$ 17,500$ million and about $\$ 1,500$ million will come from universities, non-profit institutions and so on. In terms of constant dollars, the total is expected to be about $6 \%$ below the peak spending years of the late 1960s. Measured as a proportion of the gross national product, spending on research and development has declined steadily since 1964 .

NSF has also published an estimate of the number of scientists and engineers employed in 1976, which suggests that after four years of growth, the scientific labour force now numbers 542,000 . The total is about 20,000 below the 1969 level, however. Some 40,000 science and engineering jobs were lost during the 1969-1973 cutbacks, NSF reckons.

- While the nuclear industry in the United States was licking its wounds last month, following President Carter's decision to defer commercial reprocessing and to downgrade the breeder reactor programme, a report on nuclear power plant security drew some fresh blood. Published by the General Accounting Office $(\mathrm{GAO})$, an investigatory agency of the Congress, the report concludes that "security systems at perhaps all power plants would not be able to

serve just as well. To try to limit such potential abuses, the Institute recommends that medical insurance companies should establish an advisory committee to develop criteria for paying CT scan charges. It also recommends that requests for use of CT scans should be reviewed by a physician with responsibility to control access to the machine, who would determine whether the scan is appropriate.

The central question here is not whether CT scanners are useful, but what level of investment can be justified and how the machines should be allocated and managed. Those are questions that the American health withstand sabotage attempts by threats that are now considered minimum by (the Nuclear Regulatory Commission)".

Based on inspections of security systems at six power plants, carried out by GAO investigators, the report is written in uncharacteristically blunt language, laying blame at the doors of both the nuclear industry and NRC. It states that though the quality of security forces seems to vary greatly from plant to plant, some deficiencies were encountered on each inspection. The faults included lack of training of security guards (as little as four hours at one plant), high turnover of security personnel (up to $48 \%$ a year), and poor security equipment. In particular, the report cites the following two horror stories:

We accompanied an NRC inspector to one power plant at night. The inspector asked the guard manning the guardhouse to aim a closed circuit television camera on a particular spot. The guard tried but was unable to work the system. The inspector opened a door which rang an alarm in the guard house. After waiting several minutes, the guardhouse was called to find out why no one responded to the alarm. A guard in the guardhouse answered that all of the available guards were too busy.

At yet another site, we asked a guard about the locations of certain critical systems of the plant, including the control room. He told us that the guard force knew nothing about the location of these systems because the guards were not allowed inside the power plant.

Although the NRC has recently published a set of new regulations designed to increase the effectiveness of security systems at nuclear plants, the regulations are not due to come into effect until August 1978. The GAO report says that although the new regulations are "on the right track", NRC should take steps immediately to ensure that operating plants are made more secure.

Colin Norman

care system finds difficult to address, given its fragmented nature, the competition between hospitals for revenues and prestige and the third-party payment system. As Dr Harvey Fineberg, Director of the Graduate Program in Health Policy and Management at Harvard School of Public Health put it last week, "The fundamental assumption that we in this country have not yet made is that the pot of resources available for health care is limited if you ask whether $\mathrm{CT}$ scanners are useful, the answer would be 'yes', but if you frame the question 'would they be a sound investment', you may come up with a different answer". $\square$
WEST GERMANY

\section{Energy plan published}

Werner Gries reports from Bonn on the energy research programme recently approved by the West German government

THE main emphasis of the German federal government's DM 6,200 million energy research programme for 1977 to 1980 , published at the end of last month, is on nuclear research, but the rational use of energy, progress in coal technology and the development of new energy sources are also prominent. Details of the programme, which marks the first time the state has intervened to bring together systematically both nuclear research and work on other energy resources, are as follows:

Nuclear energy will take some $75 \%$ of the state funds. Fast breeder and high temperature reactors remain the first priorities in the country's nuclear power programme, but research and development work is to continue in the fields of uranium enrichment, reprocessing and the disposal of radioactive waste. A state subsidy of about DM 1,200 million will be needed just to complete the prototype power stations now under construction to house the breeder and high temperature reactors. Reactor safety is a key aspect of the programme; R\&D on nuclear-powered ships will be continued only on a fairly modest scale, receiving about DM20 million annually.

Rational energy use: Around DM100 million annually will go into research into technologies for rational energy use. Attention will be given to techniques of remote heat supply, reverse cycle heating systems, heat recovery processes and the use of waste heat from power stations.

Coal technologies: R\&D in coal technology, one of the most important aspects of the non-nuclear side of the programme, will receive increasing amounts of funding, amounting to an average of DM140 million annually. Coal gasification, improvements to coal-fired power stations to reduce pollution, coal liquefaction and improved mining techniques will all receive support.

New energy sources: The government will support the development of new sources of energy to the tune of DM130 million a year on average, with the focus on nuclear fusion (about DM90 million annually) and on solar energy. In the government's view, solar energy is of interest in West Germany only as a means of heating build- 